\title{
Analysis of acoustic climate on board public transport
}

\author{
F. Patania, A. Gagliano, F. Nocera \& A. Galesi \\ Energy and Environmental Division of DII, Catania University, Italy
}

\begin{abstract}
The issue of thermal and acoustic comfort of passengers on board public transport has not yet been suitably faced in recent years. High-ranking of noise and improper thermal climate inside buses, trams and tubes can provoke justifiable complaints of passengers and noise impact. Noise impact may impair safety when it hinders communication inside the vehicles, causing fatigue, loss of concentration and is, obviously, annoying too. The research has been subdivided into two steps: the first is about thermal comfort and the second step has been drawn to evaluate by experimental measurements the main parameters characterizing the acoustic comfort: Equivalent sound pressure Level (Leq), Noise Rating (NR) and Speech Interference Level (SIL). All these parameters can give useful indications about the comfort status of passengers. Analysis and elaborations of measured data were taken to discover that passengers are often exposed to high levels of noise, which causes stress especially for older people and children.
\end{abstract}

Keywords: urban transport, noise control, acoustical measurements, acoustic comfort.

\section{Introduction}

Public transport plays a significant role in finding smart solutions to the challenges facing EU countries today. On this footing, increasing investment in public transportation leads not only to facility in global transfer but also to improvements in health and a better quality of life.

At the same time the main objectives in planning public transportation are:

- $\quad$ reduce traffic congestion, travel time and consequently stress;

- reduce the effects on health and environment associated with unsustainable transport patterns; 
- $\quad$ reduce and/or modify the energy consumption for mobility.

In this context there has not been an adequate public awareness about people's comfort and health on board of public transport vehicle.

In recent time some studies have focused on thermal and luminous comfort, and indoor air quality [1, 2] but acoustic comfort has been frequently overlooked.

If the target is the increase in use of public transport instead of private cars, that are more pollutant, it is necessary that subway passenger cabins and buses will be equipped with facilities that guarantee a comfortable environment as regards the noise, the light and indoor thermo-hygrometric conditions.

The indoor environmental factors to which people confer remarkable importance are temperature and humidity since these two parameters induce: quickly perceivable effects of "warm” or "cool”, "humidity air" or "dry air" [24], as well as the indoor air quality that quickly produces sensations of olfactory discomfort. Differently, the effects of noise are not quickly perceivable since some time is needed in order to perceive end organs and for the brain to perceive the discomfort sensations.

Despite the fact that in the European Union countries about $40 \%$ of the population are exposed to road traffic noise with an equivalent sound pressure level exceeding $55 \mathrm{~dB}(\mathrm{~A})$ daytime and $20 \%$ are exposed to levels exceeding $65 \mathrm{~dB}(\mathrm{~A})$ [5]. Consequently, disturbance caused by noise is a very important environmental health consequence of the transport vehicles. There is thus a great need to control noise caused by transport. Investigations of the relationship between exposure originating from different noise sources in the transport vehicles and effects among the exposed population form an important basis for technical measures to limit noise generation and to regulate noise levels. Such investigations have studied the extent of annoyance among persons exposed to different types and levels environmental noise [6].

Optimum acoustical comfort for vehicle passengers is reached with following conditions: low internal average noise; no tonal (TC) and impulsive (IC) noise components; low background noise; low peak noise; high speech intelligibility; appropriate vehicle body sound insulation. Some of the most common acoustic indices used to quantify the comfort inside an environment are the speech intelligibility, the noise equivalent level and noise rating. The authors have used those indices to evaluate the acoustic comfort of the passengers inside buses and subways cars of Catania city.

\subsection{Speech intelligibility}

Speech intelligibility is a direct measure of the fraction of words or sentences understood by a listener. The most direct method of measuring intelligibility is to use sentences containing individual words or nonsense syllables, which are read to listeners who are asked to identify them. The degree to which noise inhibits intelligibility is dependent on the signal-to-noise ratio, which is simply the signal level minus the noise level in $\mathrm{dB}$. When the noise is higher than the speech level, the signal-to-noise ratio is negative. Signal-to-noise ratio is the key to speech 
intelligibility, and it is possible to obtain more precise estimates of the potential interference by studying the background noise in the speech frequency bands [7].

The speech interference level (SIL) is a measure of a background noise's potential to mask speech.

The international community uses the speech interference level (SIL), as defined in ISO 9921-1, to rate speech communication environments. SIL is defined as the arithmetic average of sound pressure levels in the ambient environment at the 500, 1000, 2000, and $4000 \mathrm{~Hz}$ octave-band frequencies.

SIL can also be approximated by subtracting $8 \mathrm{~dB}$ from the overall $\mathrm{dBA}$ ambient level. Speech intelligibility is rated by the difference between the SIL and the A-weighted sound pressure level of speech at the listener's location. If this signal-to-noise ratio exceeds $10 \mathrm{~dB}$, that indicates satisfactory speech communication [8]. The SIL can then be compared to the expected speech sound pressure level to obtain a relevant speech to noise ratio.

Figure 1 shows the expected distance over which just-reliable communications can be maintained for various speech interference level values. The graph accounts for the expected rise in voice level, which occurs in the presence of high background noise.

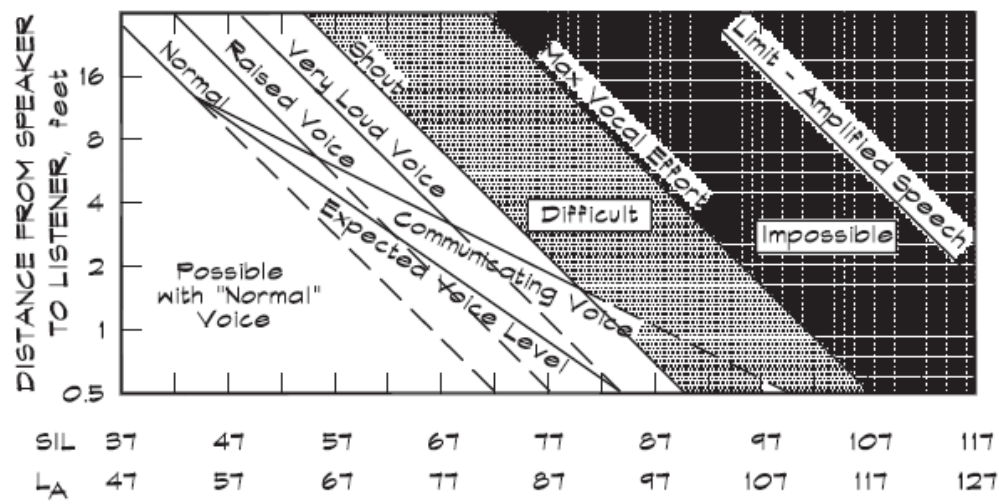

Figure 1: Rating chart for determining speech communication (Webster 1969).

\subsection{Noise Rating}

Noise Rating (NR) is a method for rating the acceptability of indoor environments for the purposes of hearing preservation, speech communication and annoyance, based on curves developed by Kosten and van Os [9].

Noise Rating curves have been adopted by the International Standards Organization [10] and they are intended for general use, particularly for rating environmental and industrial noise levels.

They are also used in many cases by machinery manufacturers to specify machinery noise levels. The Noise Rating of any noise characterized in octave 
band levels may be calculated algebraically. The NR of a noise is equal to the highest octave band noise rating $\left(\mathrm{NR}_{\mathrm{B}}\right)$ which is defined as:

$$
N R_{B}=\frac{L_{p B}-A_{B}}{B_{B}}
$$

where $A_{B}$ and $B_{B}$ are variable for octave bands between 31.5 and $8000 \mathrm{~Hz}$.

To determine the NR rating of a noise, measured octave band sound pressure levels are plotted on NR chart and the rating is determined by the highest weighting curve which just envelopes the data. If the highest level falls between two curves, linear interpolation to the nearest integer value is used.

Table 1 shows the equivalence between equivalent continuous sound levels and NR levels.

Table 1: $\quad$ Equivalence between Leq and NR levels.

\begin{tabular}{|c|c|l|}
\hline LeqdB(A) & NR & Comment \\
\hline $25-30$ & 20 & \multirow{2}{*}{ Very quiet } \\
\cline { 1 - 2 } $30-35$ & 25 & \\
\hline $35-40$ & 30 & \multirow{2}{*}{ Quiet } \\
\hline $40-45$ & 35 & \\
\hline $45-50$ & 40 & \multirow{2}{*}{$\begin{array}{l}\text { Moderately } \\
\text { Noisy }\end{array}$} \\
\hline $50-55$ & 45 & Noisy \\
\cline { 1 - 2 } $55-60$ & 50 & \multirow{2}{*}{ Noisy } \\
\cline { 1 - 2 } $60-65$ & 55 & \\
\hline $65-70$ & 60 & Noisy \\
\hline
\end{tabular}

In Table 1, the $\mathrm{dB}(\mathrm{A})$ levels equivalent to an NR level were calculated by considering levels only in the $500 \mathrm{~Hz}, 1000 \mathrm{~Hz}$ and $2000 \mathrm{~Hz}$ bands, and assuming a spectrum shape specified by the appropriate NR curve [11].

\section{Survey methodology}

The experimental survey was carried out on one bus route and one subway route of Catania City. More specifically, the survey was focused on the subway line number 432 (3.2 km) and on the bus lines number 449 and $429(3.7 \mathrm{~km})$.

The campaign of measurements was carried out for 18 consecutive days in July at different period of time: 8:30-9:30, 11:30-12:30, 15:30-16:30, 18:3019:30. Acoustic measurements were taken in running buses using a class 1 , Norsonic sound level meter, which was placed at $10 \mathrm{~cm}$ from driver's right-hand auditory zone [10] and from $15 \mathrm{~cm}$ from passengers' right-hand auditory zone.

For each single session of measurements were also reported general data (route, date, time, travel time, waiting time of the stop, etc.), details of the vehicle (model, number of passenger, total seats). The results of acoustic measurements were elaborated using the software "Nor 1.0 Review". For each session of measurement, the equivalent noise level, the frequency spectrum, the 
time history of equivalent continuous sound level were calculated and analyzed. The Noise Rating (NR) was calculated overlapping the measured frequency spectrum on the NR chart (see figure 2).

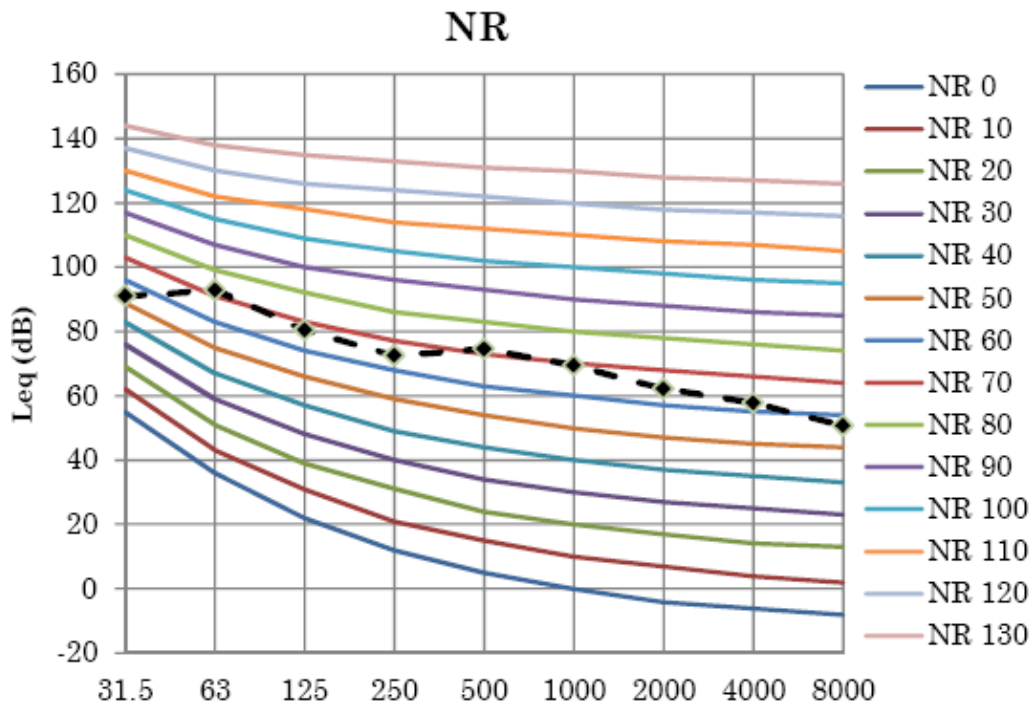

Figure 2: $\quad$ Exemplum of NR curve.

The Speech Interference Level was calculated by the arithmetic average of sound pressure levels in the ambient environment at the 0.50, 1.0, 2.0, and $4.0 \mathrm{kHz}$ octave-band frequencies. Figure 3 shows the time history of equivalent continuous sound level measured during one session of measurements.

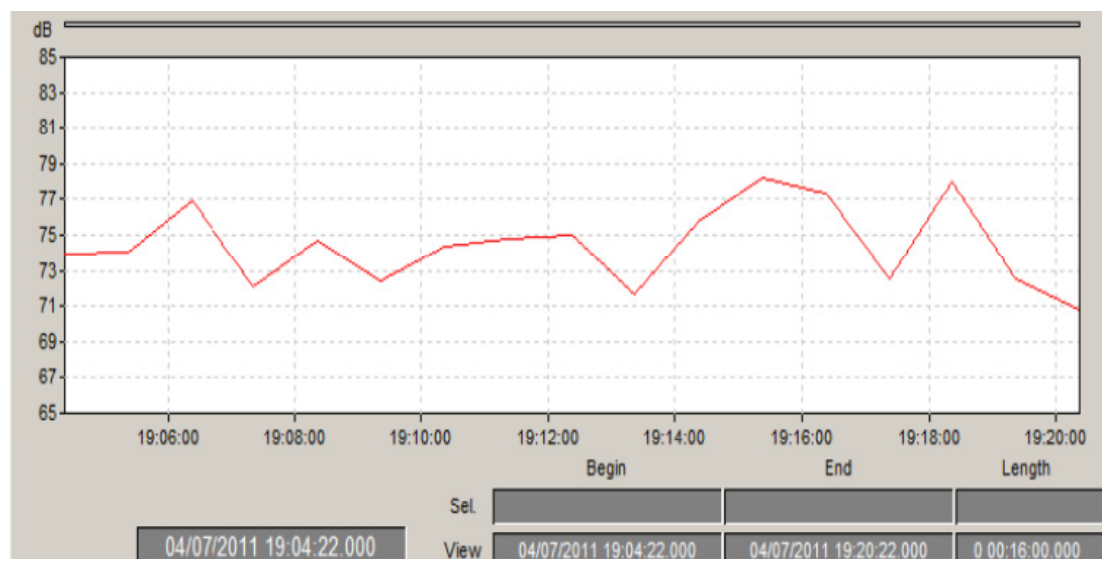

Figure 3: Exemplum of time history of equivalent continuous sound level. 
It is possible to notice that the sound pressure levels are related to noise generated by vehicles (accelerating, change gears and braking) and to the noise generated by the other vehicle nearby the bus.

The summary of measurements and results for the subway car and bus are reported in figures 4 and 5.

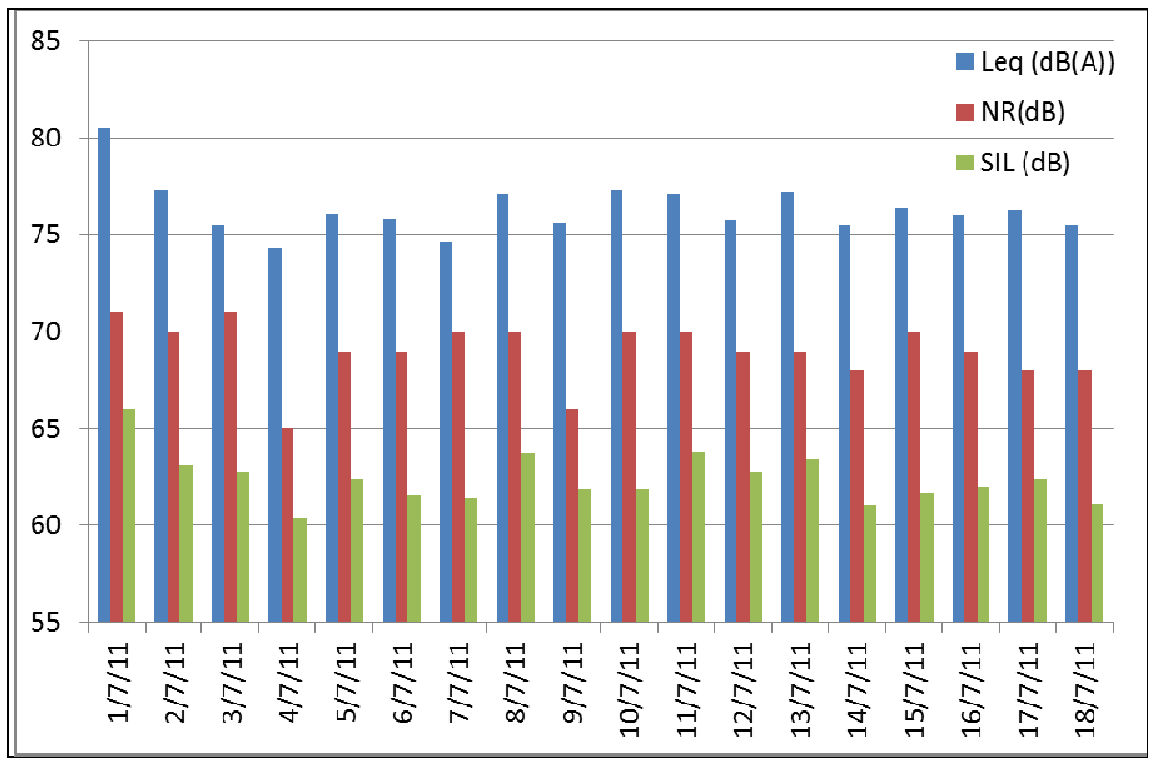

Figure 4: $\quad$ Summary results for the subway route.

The analyses of survey data indicate the acoustic indices are very similar for both the subway route and the bus route.

With reference to the NR index it can be noted that passengers are exposed to values always higher than $62.0 \mathrm{~dB}(\mathrm{~A})$, with an average values of $70.0 \mathrm{~dB}(\mathrm{~A})$, which are values that indicate a very noisy environment, like workshops for example.

With reference to the SIL, it can be noted that this index assume values always higher than $59.0 \mathrm{~dB}(\mathrm{~A})$, with an average values of $63.5 \mathrm{~dB}(\mathrm{~A})$, values that indicate again a very noise environment. In fact, just for a distance of one meter between source and listener the speech intelligibility is really compromise.

With reference to the Equivalent Continuous Sound Level (Leq), it can be noted that passengers are exposed to values of Leq always higher than $72.0 \mathrm{~dB}(\mathrm{~A})$, with an average values of $77.0 \mathrm{~dB}(\mathrm{~A})$.

These values are very high value, in fact if we compare it with the value limit set by Italian legislation in the field of acoustic pollution, they are higher than the limit fixed for industrial area.

Globally, all the measurements data and the acoustic indexes indicate very discomfort conditions and an unacceptable acoustic climate. 


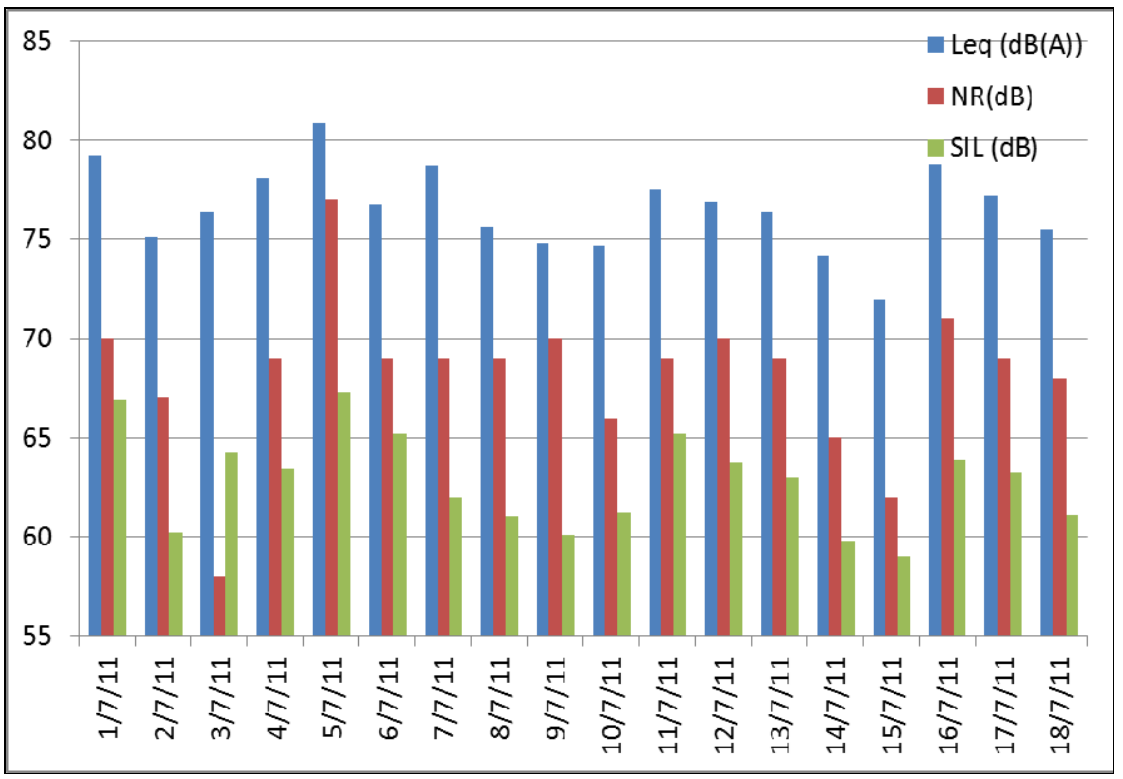

Figure 5: $\quad$ Summary results for bus route.

Considering the Italian legislation, the passengers are exposed to very high levels of noise, while the driver is exposed to values below the limit of legislation.

The noise levels inside the buses and subway cars do not differ much more from the noise levels outside them, but in any case it would be desirable to provide soundproof interventions of the cabins in order to improve passenger comfort.

Moreover, a previous study on thermal comfort inside public transportation, showed that the thermal climate inside bus and subway car were also inadequate [1]. The results of these researches permit to highlights the needs to improve both the acoustic and thermal comfort may attract the use of public transport in place of private cars.

\section{Conclusions}

The experimental survey highlight the values of acoustic indices, both inside the bus and subway car assume values, for all the measurements, higher than the minimum acceptable values for a sufficient acoustic comfort. The values of the calculated acoustic indices are very similar for both the subway car and the bus.

With reference to the average values, it is evident the acoustic discomfort inside the bus and subway car, in fact:

- Leq is far above the value of $65 \mathrm{dBA}$, which can be considered acceptable in urban areas with intense human activity. 
- NR index assumes values characteristic of very noisy environments such as carpentries and/or craft workshops.

- SIL assumes values that may require a high tone voice of the passengers in order to have a minimum value of speech intelligibility.

- The noise levels inside the buses and subway cars do not differ much more from the noise levels outside them but, in any case, it would be desirable to provide soundproof interventions of the cabins in order to guarantee the improvement of passengers' comfort.

- The results of research in this field permit us to highlight the needs to foresee intervention to improve both acoustic and thermal comfort.

From the above, it is easy to conclude that an adequate acoustic and thermal climate may contribute to attract and incentive the use of public transport.

\section{References}

[1] Patania, F., Gagliano, A., Nocera, F., Galesi, A., Thermal comfort analysis of public transport passengers in Catania, (2012) WIT Transactions on Ecology and the Environment, 157, pp. 327-338

[2] Patania, F., Gagliano, A., Caponetto, R., Nocera, F., Galesi, A., A Neural Network model for the estimation of bioclimatic indexes, (2010) WIT Transactions on Ecology and the Environment, 136, pp. 237-247.

[3] Patania, F., Siracusa, G., Gagliano, A., Nocera, F., Air quality inside cars moving into urban traffic in Catania city: The exposure to the carbon monoxide, (2002) Advances in Air Pollution, 11, pp. 663-672.

[4] Patania, F., Gagliano, A., Nocera, F., Galesi, A., Thermal comfort in operating rooms: A case study, (2011) WIT Transactions on Biomedicine and Health, 15, pp. 105-114

[5] WHO (World Health Organization), The Environmental Health Criteria Document on Community Noise, 1992

[6] S. R. Kumbhar, S. S. Sarawde and Bimlesh Kumar Structure-Borne Noise and Vibrations in Automobiles: An Overview International J. of Engg. Research and Indu. Appls. (IJERIA). ISSN 0974-1518, Vol.3, No. II (May 2010), pp 431-443

[7] Marshall Long Architectural Acoustics Elsevier Academic Press 2009.

[8] Thomas D Rossing Springer Handbook Springer 2007.

[9] Kosten and Van Os. Community Reaction Criteria for External Noises. National Physical. Laboratory Symposium No. 12. HMSO, 1962.

[10] Acoustics determination of occupational noise exposure and estimation of noise induced hearing impairment: ISO 1999-1990.

[11] David A. Bies, Colin H., Hansen Engineering Noise Control Spon press, 2008. 